\title{
Protocol of Job Evaluation: A Bird's Eye View
}

\author{
Muhammad Ali EL-Hajji (Ph.D) \\ Former Lecturer of Liverpool John Moores University \\ $\&$ \\ Liverpool Community College, England - UK \\ E-mail:maelhajji@hotmail.com
}

Accepted: December 2, 2011 Published: January 9, 2012

doi:10.5296/ijhrs.v2i1.1248 URL: http://dx.doi.org/10.5296/ijhrs.v2i1.1248

\begin{abstract}
Job evaluation has become one of the most systematic and rational paths for an organization's fair and equitable wage and salary determination. It has become a reality within an organization's wage and salary administration. This article tries to investigate the inside concepts, dimensions, premises, and process of job evaluation. It extends to include the universality of job evaluation as a common phenomenon in organizations, particularly large ones. In view of this, this article explores and discusses the variety of ways in which job evaluation is viewed and defined. It also provides a sound understanding of the theoretical / philosophical context of job evaluation. In so doing, the article examines the combination of the conceptual and technical aspects involved in the job evaluation process, which demand good management sense and skill.
\end{abstract}

Keywords: Job evaluation, Dimensions, Jobs comparison, Prerequisites, Relativities, Different views, Elements and Stages, Universality.

\subsection{Definition of Job Evaluation:}

There is an array of definitions of job evaluation presented in the literature. Although they all cover common ground i.e. a great deal of similarity exists between them, it is however, not possible to integrate them all into one common definition. Nor is it realistic to judge which is best. This neither, nor should, prevent other writers or researchers on job evaluation from presenting their own views and definitions (as we have done), for such endeavors serve to enrich the concept of this domain. In short, the variety of definitions should not be seen as competing against each other but, rather, complimenting each other. As a consequence the reader is provided with a more comprehensive picture of job evaluation and a better understanding regarding its concept, dimensions, and premises. 
Job evaluation is a term used to cover a number of different formulae so as to determine the relative worth or size of the jobs upon the basis of the content and demands of the job itself, and not on the basis of supply and demand pressures, collective bargaining or bargaining by agreement. In other words, job evaluation is a general term used to cover a number of distinct methods for systematically assessing the relative worth of jobs, within an organization, by employing yardsticks which are derived from the actual content of those jobs. In so doing, job evaluation can be seen as a way of rating the value of the jobs to the organization concerned. [See Thomason, 1976; Thomason, 1968; Thomason, 1980; Rands and McBeath in "Personnel Management" (IPM), 1969; British Institute of Management (BIM), 1970; London Boroughs' Management Service Unit (LBMSU) 1971; Thakur and Gill, 1976; Elizur, 1980; ACAS, 1982; Torrington \& Hall, 1991; Pritchard and Murlis, 1992; Jewell, 1993; IRS, 1998; Foot and Hook, 1999; Bratton and Gold 1999; Boxall and Purcell, 2003; Armstrong, M. 1998; Armstrong, et al., 2003; Armstrong, 2007].

However, there is a need to be more specific as to the definition of job evaluation. Hence, job evaluation as a term refers mainly to the following:

Job evaluation is a process of systematic measurement of the job's relative value, designed and developed through holding thorough job comparisons to establish a hierarchy of job differentials, job relativities, and job grading accordingly to achieve internal pay consistency - thus it is an attempt to remove pay anomalies, disordered, irrational or illogical pay differences and to create a fair pay system. This requires job evaluation to act as a procedural aid to pay equity for work of equal value and is a very useful means for pay determination that can be used towards establishing a wage and salary structure. This means job evaluation itself does not determine pay structure. Nor does it dictate the final payment level for a job. It must be emphasized that job evaluation does not determine the actual/total/final pay. That is a separate operation which usually involves negotiation between management and union representatives and takes into account external factors, such as levels of pay in a given locality or industry (wage survey / market survey). Rather it (job evaluation) is a measure to determine the pay gap differentials and produce them in a systematic ranking of jobs upon which a pay structure can be built and final pay levels (jobs' prices) are determined. Thus, in its most simple form, job evaluation is a job-value assessment technique providing a form of logical hierarchical order of jobs in relation to their relative contributions to the organization. Consequently, it considers the value of jobs themselves in relation to each other and takes no account of the employee's characteristics. In addition, job evaluation not only has the merits of being systematic but also of appearing as objective as possible. Briefly, looking at the process of job evaluation from where it finishes, it can be said that job evaluation is an orderly and systematic process of internal job pricing based on job relativities and internal pay equity (For further definitions and views see point 3.0 below).

\subsection{The Importance of Using SAME Standards or Criteria for Making Job Comparisons}


Accordingly, job evaluation is a technique used to evaluate different jobs with the same standards or common criteria with a proper utilization for their respective job descriptions to ensure consistency. Otherwise, if judgments about the relative value of jobs were to be based upon different criteria or standards, inconsistency would result and job comparison would be like comparing apricots with pomegranates, or walnuts with grapes, or watermelons with oranges, or even, (in the words of Barry Cushway, 1999: 137) "eggs with apples". Thus the job evaluation process must be a coherent and consistent set of procedures with specific and predetermined objectives. It is not, and never will be, fully objective nor purely scientific for both (subjectivism and scientific-ism) are relative and born out of what is, after all, a process of human origin, and it will stay so as log as the process and the results are involved in the exercise of human assessment / value judgement or personal values of the parties that conduct it (for further illustration and discussion see El-Hajji, 2011). Hence, from an organization perspective, job evaluation is not an end in itself but a means to an end. It is largely viewed as a management prerogative device.

\subsection{Dimensions of Job Evaluation}

This shows that job evaluation can be seen to fall into three dimensions. These are Content, Process, and Structure:-

(1) Content refers to what constitutes job evaluation. It includes the subject matter, ideas, aims and principles or elements that job evaluation contains or covers.

(2) Process refers to the relationships and communication between the parties concerned with the job evaluation and to the decision-making mechanism.

(3) Structure refers to the last phase of the job evaluation process in which jobs have been priced systematically; for job evaluation essentially is concerned with the internal relativities / internal consistency / internal equity. And by so doing, job evaluation proves its importance as a base to the organization's wages and salaries structure.

\subsection{Premises of Job Evaluation}

Analysis of the above shows what the vital premises of job evaluation are. It might therefore be useful to identify these basic premises:-

(1) The focus is to be on the actual (current) job content as it is today or at the time of evaluation. Job evaluation shows no consideration for the worker's capabilities or personality.

(2) Each job should be broken down into its component parts.

(3) Job analysis, thus, needs to be a systematic investigation of a job in order to define its essential characteristics.

(4) The individual components of a job need to be available, and stated clearly, in the form of a job description. 


\section{Macrothink Institute ${ }^{\text {TM }}$}

(5) The relative worth of each job needs to be determined through the evaluation process so that jobs may be graded in relation to their relativities. It is worth reemphasizing that the determination of internal relativities is normally done in a form of job evaluation. There is also a need to take into consideration a reconciliation of internal external job consistency.

(6) Pay equity for work of equal/similar/equivalent value or importance.

(7) Since the job evaluation process affects both organization and employees, management-employees joint efforts and cordial relations are necessary.

(8) No matter how it is performed, inevitably, job evaluation is a systematic judgmental process.

(9) It cannot be applied to one job exclusively since the nature of job evaluation is inconsistent with exclusiveness or isolationism.

\subsection{Job Evaluation's Prerequisites}

Appropriate job analysis and job description are essential, or rather inevitable, in setting up, on a firm footing, a wage and salaries scheme in any organization. While job description is the basic document of job analysis, the latter, in turn, is the basic document or factual foundation of job evaluation. i.e. Job analysis is a technique for determining the basic elements of a job. While job evaluation is a vital foundation upon which the structure of wages and salaries rests, wage and salary structures are an essential instrument developed to translate and/or reflect the organization's remuneration policy into a formal hierarchy of given grades and levels. However all three terms namely: job analysis, job description and job evaluation are practical works of study for existing jobs. 
2.1 Key Elements in, and the Main Steps of, the Job Evaluation Process

\subsubsection{Key Elements in Job Evaluation Process (in Diagram):}

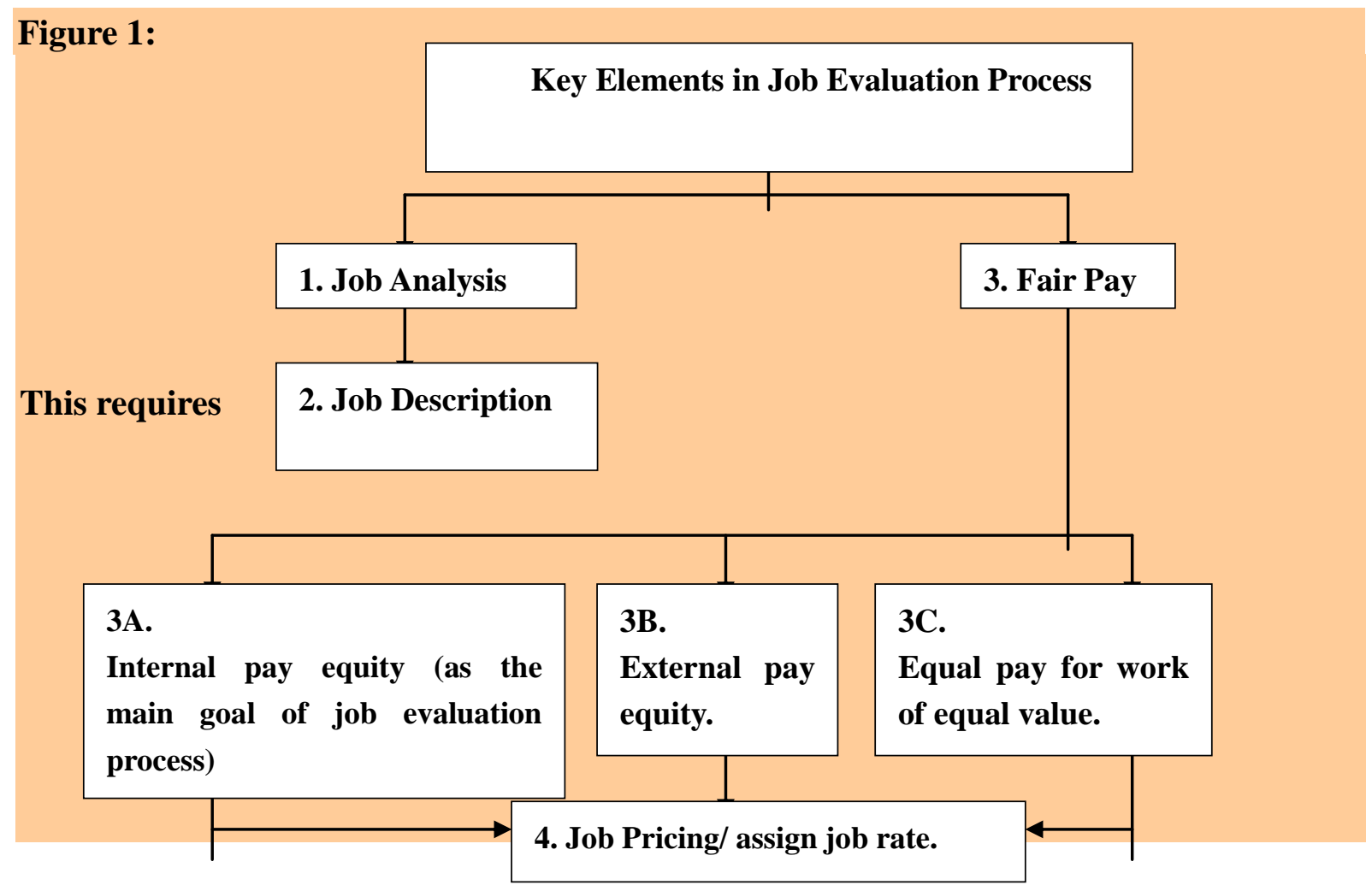

\subsubsection{Job Evaluation Steps (in points):}

Job Evaluation process consists of the following major steps:

1. Specifying/ identifying the job(s) to be evaluated- with all of its tasks, duties and responsibilities.

2. Collecting data and information about the job(s) to be evaluated.

3. Selecting job factors.

4. Measuring and assessing the job(s).

5. Assigning the job's rate - job pricing.

\subsection{Job Evaluation: Different Views For The Same Concept}

The above illustration of job evaluation definitions shows that there are several interpretations of the term. All such meanings and definitions are closely interrelated and revolve around the same framework. This depends on: (a) the point of view of the parties concerned - their work, positions, and strategic background, and (b) the organization's policy and purpose behind adopting and launching job evaluation. The following are examples of such views: - 
(1) Job evaluation is a technique of job classification based on job analysis; job similarities and dissimilarities, and job relativities, in the light of certain selected job factors.

(2) Job evaluation is a systematic device for regulating the pay system of an organization - through comparable hierarchy of jobs worth.

(3) Job evaluation is a double-edged device, which may be used as a threat to collective bargaining.

(4) Job evaluation is a systematic technical process in a dynamic sociopolitico-economic context to achieve fair pay. It therefore involves moral, ethical and environmental aspects. It is a dynamic process so it is revised periodically.

(5) Essentially job evaluation is a process of establishing a hierarchy of depersonalized job values arranged according to job differentials for providing equity of pay. Yet, it is, largely, a judgmental process of job content based on the comparison between the relative values of the jobs.

(6) Job evaluation, basically, is a technical approach for wage differential solving problems through a joint effort of the parties involved. It reduces the impact of these problems but does not totally eliminate them.

(7) Job evaluation is a systematic (internal) jobs pricing process based on the relative values of jobs/ internal equity - through assigning a monetary value to the importance of a job. This definition is illustrated in Fig. 2 below. 


\section{Figure 2: (Internal) Job Pricing Process: A View of looking at Job Evaluation}

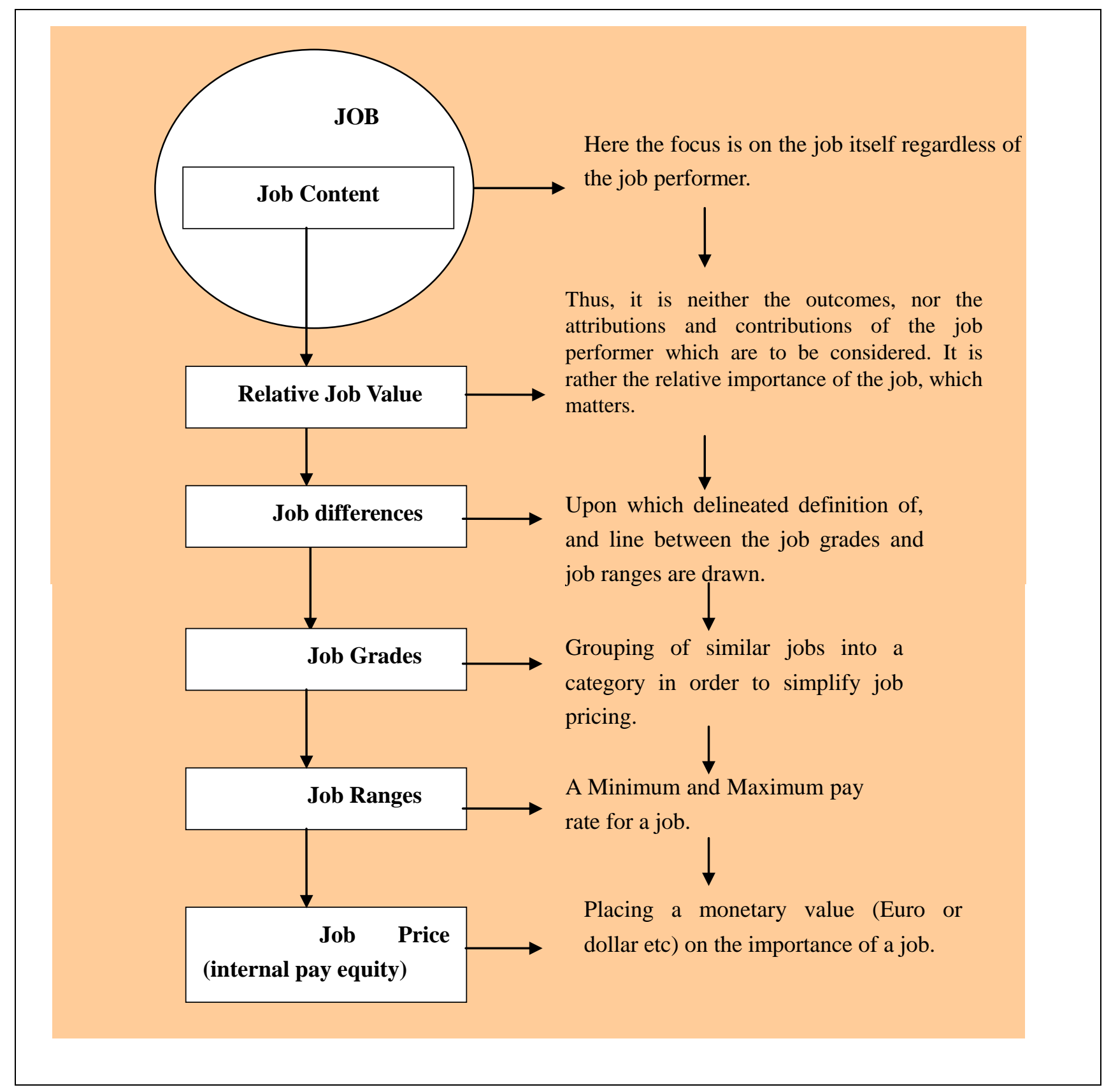


To simplify this view, in the figure above, the process of job evaluation has been viewed from three integral or rather integrated positions. They represent the stages that the job evaluation process goes through, where each stage or position is a prerequisite to the one that it succeeds.

These are as follows:

(a) Looking at the process of job evaluation from where it starts (i.e. from the initial stage) job evaluation is a systematic process of job analysis and job description in order to rank the jobs in a hierarchical order of their importance.

(b) Looking at the middle of the job evaluation process, job evaluation is about placing jobs into levels, grades and scales, i.e. it is a job grading or job classification process.

(c) Looking at the end of the job evaluation process, (i.e. from where it concludes), job evaluation is a systematic procedure (a means) of internal jobs pricing -internal equity- though it does not determine the actual (final) pay for the jobs.

Clearly, most of these views or definitions present or render job evaluation as a multi-phase process that requires the evaluator to follow it in order to complete the whole process. However, most of the job evaluation definitions provided in the management literature take a form of description of its objectives, purpose, advantages and the stages of its process. That is often the case, even among the specialists and/or the managers when they look at job evaluation. Having said that, it is important to remember that, management of the organization and job evaluators have to consider some ethical issues and concepts that associate with all phases of job evaluation process such as fairness, equity, objectivity and gender pay-free discrimination.

\subsection{Different People Have Different Views}

Hence, the views, for instance, of management (line manager, human resource manager), job evaluation specialist or expert, employee, union and academician may differ from each other in some aspects. Such contrasting views need not mean that one view is right and all the rest wrong. Invariably these views will cover the same, common ground. Consequently, the differences are usually those of emphasis rather than content. Different expressions may be used but will nonetheless refer to the same subject matter. Very often the main differences lie in selecting which issues take prominence over the rest and in what hierarchical order. Thus the views may be as diverse as the route to Rome but the destination remains clear and specific in the mind of the traveler (in this case the evaluator).

In short, having many definitions of job evaluation remind us of a Chinese proverb that "there are many paths to the top of the mountain, but the view is always the same". That is, the basic idea of job evaluation is to find out or identify the job's relative value to the organization in order to justify the rate or pay difference between the current jobs, whether we use analytical or non-analytical techniques. 
Milkovich and Boudreau (1998) summarize the differences in definitions and views of job evaluation in that they "are as diverse as the blind men's elephant". All parties, explicitly and/or implicitly, believe that job evaluation after all is a rational and systematic process of allocating jobs to levels based on the skill, effort, and responsibility factors that form the job's contribution to an organization. They also believe that, if done successfully, it will serve all parties concerned.

\subsection{Universality of Job Evaluation}

With any organization (particularly big ones), and in any economical system, be it socialist or capitalist or mixed, setting rational and equitable employees' wages is extremely important and useful for all parties involved. Looking into and through the literature of personnel/human resource management and industrial relations, some key words are found and repetitively used. Examples of such key words and phrases are the ranking and rating of jobs, ranking jobs or ordering them into a hierarchy, and rating or pricing jobs in relation to their relative value.

Job evaluation of some kind is a universal phenomenon in any organization's pay, wage and salary structure. For example, if the manager of an industrial company decides that the operator should receive more than the typist; the jobs have already been evaluated. Thus, job evaluation occurs whenever decisions are made concerning the relative worth of jobs. That is because job evaluation is essentially a procedure or technique of introducing / setting up or establishing the relative value (comparative worth) of the jobs, using criteria extracted or drawn from the nature / content and demand of the jobs themselves. The decision of what wage should be fixed for each job can be greatly facilitated by the determination of the relative worth of jobs. It is important that this decision be based upon sound, objective judgments and not on informal, misguided or subjective estimations. This shows that for management to systemize the organization's order of pay ranking, it has to use job evaluation as a tool to accomplish this task. Thus job evaluation is viewed by businesses as "a rational way of working out why some jobs are paid more than others"(Hall, D., et al., 2004).

Hence, Job evaluation has been gaining more and more attention in spite of its relatively brief history. Surveys of various sectors and industries in different countries emphasize the need of organizations for job evaluation.

According to the National Board for Prices and Incomes in Britain, the need for job evaluation is mainly to offer an accepted pay structure (National Board for Prices and Incomes, Sep., 1968; also Graham et al., 1976). In a survey of 316 organizations found that 55 percent used formal job evaluation processes (Armstrong, 1999/2000). [ In a similar context, Penny Hackett, 1979, mentioned in a general statement that more than half of Britain's largest companies (i.e. those employing more than 5000 workers) and more than a third of those employing between 500 and 5000 workers use some form of job evaluation]. 
In the U.S.A. one third of American companies have adopted formal job evaluation plans (Calhoon, 1963). Six out of every seven firms covered in a survey by the Bureau of National Affairs used formal job evaluation plans (details in Belcher, 1974; see also Thakur and Gill; Figart et al., 2002).

Europe, too, embraces job evaluation more than Britain, with the Netherlands being a case in point. What is clear is that whilst the degree of job evaluation application varies greatly from country to country, its overall use continues to increase at a considerable rate (Brown et. al., 1972). From here, strictly in this context, one can safely say that job evaluation is, in a way, a universal phenomenon in organizations pay systems.

\subsection{Summary}

Job evaluation is a rational and systematic process of evaluating an organization's jobs' contribution in terms of their relative value/compensable worth. That is to say, job evaluation is a means to measure, to assess, to compare and to define the relative value of jobs within an organization. This applies whether the organization is a single plant or spread across multiple sites and emphasis is placed upon the importance of using the same standards or criteria for maintaining job comparison

The focus of job evaluation is on achieving internal wage consistency (internal equity) as the ultimate objective. Thus it does not focus on the work volume of the employee or the number of people needed to carry out the job, or the ability of the job occupier/ the individual worker's specifications or market place rates.

Job evaluation is a multi - phase process. Its results can bring harmony and peace of mind or disruption which can be a source of many problems, dependent upon the approach adopted and level of professionalism implemented. From beginning to end, the job evaluation process represents both a management and a conceptual challenge for the parties who are either in charge or directly involved.

As a bare minimum a professional, impartial approach is necessary in the process is to be successful. Accordingly, the process of job evaluation can be seen as a mixture of technical and conceptual aspects requiring good management sense and skills. All things considered job evaluation, where appropriately applied, has become one of the most systematic and rational paths that an organization can follow in its efforts to determine a fair and equitable salary and wages structure. Today it is seen as a common phenomenon that produces tangible, progressive outcomes of an organization's administration of its salary and wages distribution for it provides the appropriate answer to the thorny question of measuring and determining wage differences. 


\section{References}

[1] Advisory, Conciliation and Arbitration Service (ACAS.) (1982) Job Evaluation, revised, London: for H.M.S.O by The Holly Press LTD.

[2] Armstrong, M.; Cummins, A.; Hastings, S.; Wood, W. (2003) Job Evaluation A Guide To Achieve Equal Pay, London: Kogan Page Limited

[3] Armstrong, M. (1999/2000) Employee Reward, $2^{\text {nd }}$ ed., London: Chartered Institute of Personnel and Development (CIPD).

[4] Armstrong, M. (2007) A Handbook of Employee Reward Management And Practice, 2ed, Britain: Kogan Page Limited

[5] Armstrong, M. (1998) A Handbook of Personnel Management Practice, $6^{\text {th }}$ ed., London: Kogan Page.

[6] Belcher, D.W (1974) Compensation Administration, $3^{\text {rd }}$ ed., New Jersey: Prentice-Hall, Inc.

[7] Boxall, P. \& Purcell, J. (2003) Strategy and Human Resource Management, Britain: Palgrave Publishing Limited

[8] Bratton, J. and Gold, J. (1999) Human Resource Management Theory and Practice, 2nd ed., Britain: Macmilan Business

[9] British Institute of Management (BIM), (1970) Job Evaluation; A Practical Guide for Managers, London: Management Publications Ltd.

[10] Brown, E.H.P.; de Jong, Dr. J.R., Fisher, P.; Thomas, R.E. \& Webb, G. (1972) Some Approaches to National Job Evaluation, London: Foundation for Business Responsibilities.

[11] Calhoon, R.P. (1963) Managing Personnel, New York: Harper.

[12] Cushway, B. (1999) Human Resource Management ,revised edition, Britain: Kogan Page.

[13] El-Hajji, M. A. (2011) What Job Evaluation Is Not: Dispelling the Doubt, International Journal of Business and Social Science, Vol. 2 No. 3 [Special Issue - January, 131-136].

[14] Elizur, V. (1980) Job_Evaluation: A Systematic Approach, Britain: Gower Publishing Company Limited. 
[15] Figart, D. M.; Mutar, E. and Power, M. (2002) Living Wages, Equal Wages: Gender and Labor market polices in the United States, Britain, Routledge

[16] Foot, M. \& Hook, C. (1999) Introducing Human Resource, $2^{\text {nd }}$ ed. Britain, Pearson Education Limited.

[17] Graham, H. T.; Maconal \& Evans Ltd. (1976) Human Resources Management, London.

[18] Hackett, P. (1979) Success In Management: Personnel, London: John Murray (publishers) Ltd.

[19] Hall, D.; Jones, R.; Raffo, C.; Chambers, I. \& Gray, D.(ed), (2004/2006) Business $\underline{\text { Studies, }} 3^{\text {rd }}$ ed., Britain: Pearson Education Limited.

[20] IRS (1998)) There is value in job evaluation, IRS Employment Trends 665, October.

[21] Jewell, B.R. (1993) An Integrated Approach to Business Studies, London: Pitman Publishing.

[22] London Borough's Management Services Unit (LBMSU) (1971) Job Evaluation, London.

[23] Milkovich, G.T. \& Boudreau, J.W. (1988) Personnel/Human Resource Management -A Diagnostic Approach, $5^{\text {th }}$ ed., U.S.A.: Business Publications, Inc.

[24 National Board for Prices and Incomes (NBPI), (Sept. 1968) Job Evaluation Report No. 83, London: H.M.S.O.

[25] Pritchard, D. and Murlis, H. (1992) Job, Roles And People, London: Nicholas Brealey Publishing Limited.

[26] Rands, N. \& McBeath, G.(1969)'Can Fair Comparison of Jobs and Their Pay Rates be Made Across a Whole Industry?' Personnel Management, the Journal of the Institute of Personnel Management, Vol. 2, No. 4.

[27] Thakur, M. \& Gill, D. (1976) Job Evaluation in Practice. A survey of 213 organizations in the UK, London: Institute of Personnel Management - Management [currently called Chartered Institute of Personnel and Development (CIPD)].

[28] Thomason, G. F. (1976) A Textbook of Personnel Management, London: Institute of Personnel Management (currently CIPD).

[29] Thomason, G. F. (1968/1976) Job Evaluation, London: Institute of Personnel Management - currently (CIPD). 
[30] Thomason, G. F. (1980) Job Evaluation: Objectives And Methods, London: Institute of Personnel Management (presently CIPD)

[31] Torrington, D. and Hall, L. (1991)) Personnel Management A New Approach, $2^{\text {nd }}$ ed., Britain: Prentice-Hall International (UK) ltd. 